\title{
Clinical and radiological characteristics of forearm deformities in children with multiple hereditary exostoses
}

\author{
E.A. Zakharyan ${ }^{1}$, E.A. Belousova ${ }^{2}$, A.P. Pozdeev ${ }^{1}$
}

\author{
${ }^{1}$ The Turner Scientific and Research Institute for Children's Orthopedics, Saint Petersburg, Russian Federation \\ ${ }^{2}$ North-Western State Medical University named after I.I. Mechnikov, Saint Petersburg, Russian Federation
}

\begin{abstract}
Introduction The incidence of forearm deformities in children with multiple hereditary exostoses (MHE) ranges from 30 to $80 \%$. There are few studies of deformities of the forearm in MHE patients in the literature that describe not only the location of exostoses and position of the head of the radius but also the true variants of forearm deformities. The aim of the study was to investigate forearm bone deformities in patients with multiple hereditary exostoses. Materials and methods Radiographs of the bones of the forearm in 84 patients (151 limbs) diagnosed with multiple hereditary exostoses in the age of four to 17 years who were treated at our institute from 2004 to 2018 were retrospectively analysed. The study involved 47 boys and 37 girls; 67 patients (80 \%) had bilateral lesions, and 17 patients (20\%) had lesions of only one upper limb. Patients were divided into four groups depending on the type according to the Jo\& Jung's classification. The deformities were evaluated based on radiological methods in accordance with the reference lines and angles for the forearm bones. Results The most common variants of forearm deformities were revealed: varus recurvatum at the border of the upper and middle third of the ulna (55\%), varus recurvatum at the border of the upper and middle third of the ulna associated with varus of the radius in the middle third (15\% of cases); as well as their combinations accompanied by dislocation or subluxation of the radial head (30 \%). RAA (radial articular angle) and RB (radial bowing) did not have significant difference in various types of deformities of the forearm according to Jo\&Jung's classification. Conclusion The study of the variety of forearm deformities in children due to multiple hereditary exostoses will assist in a differentiated approach to the choice of surgical treatment methods depending on the type of deformity.
\end{abstract}

Keywords: multiple hereditary exostoses, forearm deformities, classification

\section{INTRODUCTION}

Multiple hereditary osteochondromas (HMO) also known as multiple hereditary exostoses (HME) is a genetic autosomal dominant inherited disorder of the human skeleton; primary spontaneous mutations are observed in 20 to $30 \%$ of cases. Its incidence is $1: 50,000$ newborns. The pathology may manifest itself already in infants of the first year of life.

Multiple osteochondromas is a frequent pathology in the pediatric practice. Its incidences make from 16 to $43 \%$ of all cases of tumours, tumour-like and dysplastic bone diseases, as reported. Deformities of forearm develop due to multiple exostoses in 30 to $80 \%$ of cases: ulnar ( $83 \%$ ) and radial (17) club hand among them [1, 2, 3]. Limb length discrepancy, angular deformities, and decrease in the range of motion in the adjacent joints as well as pain due to local irritation of muscles, tendons and nerves due to exostosis are observed. Progression of angulation may result in instability in the elbow and wrist joints.
Three classifications that reflect deformities of the forearm bones due to HMO were found in the literature sources on this topic.

The classification developed by A.P. Pozdeev and L.Yu. Khodzhaeva is based on the ulnar deviation of the hand, restriction of movements in the adjacent joints, presence/absence of deformities of the bones of the forearm, magnitude of the forearm shortening, presence/absence of rotation restriction, decentering /subluxation /dislocation of the radial head. Thus, they distinguish five grades of ulnar club hand [3]:

Grade I: ulna deviation within $10-15^{\circ}$. The hand acquires its central position actively or passively, full range of motion in the adjacent joints;

Grade II: ulna deviation up to $30^{\circ}$. The hand acquires its central position actively or passively; there is arch-like deformity of the forearm bones and its shortening up to $2.5 \mathrm{~cm}$; restricted rotation due to decentering and radial head subluxation;

Zakharyan E.A., Belousova E.A., Pozdeev A.P. Clinical and radiological characteristics of forearm deformities in children with multiple hereditary exostoses. Genij Ortopedii, 2019, vol. 25, no 4, pp. 487-492. DOI 10.18019/1028-4427-2019-25-4-487-492. (In Russian) 
Grade III: ulna deviation is more than $30^{\circ}$. The hand does not acquire the centered position; forearm bones deformity and its shortening up to $3 \mathrm{~cm}$, sharp restriction of rotation due to subluxation and full dislocation of the radial head;

Grade IV: ulnar deviation more than $30^{\circ}$; the hand does not acquire the centered position; full dislocation of the radial head; deformities of both forearm bones; rotation within $10-15^{\circ}$;

Grade V: ulnar deviation not more than $30^{\circ}$, lesions of distal parts in both bones; dislocation of the redial head; deformity of the metadiaphyses of both bones; considerable shortening of the segment, muscle hypotrophy, flexion contracture of fingers.

The second classification was developed by Masada and Ono, and evaluates the relationship of osteocartilaginous exostoses location and presence/ absence of radial head dislocation (Fig. 1) [4, 5]:

Type I: osteocartilaginous exostoses are located in the distal ulna and there is no radial head dislocation;

Type IIA: radial head dislocation and osteocartilaginous exostoses in the proximal methaphysis of the radius, shortening of the ulna;

Type IIB: osteocartilaginous exostoses are located in the distal ulna associated with radial head dislocation, no ulna shortening;

Type III: osteocartilaginous exostoses are located in the distal radius, without radial head dislocation, shortening of the radius.

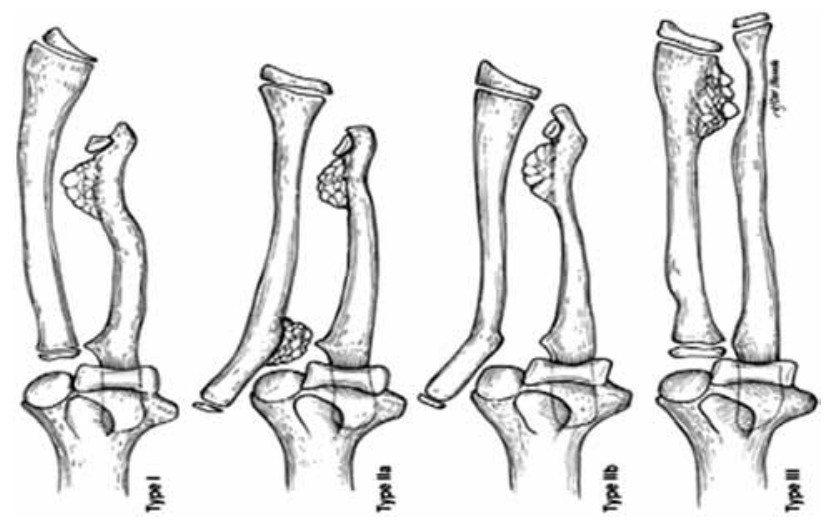

Fig. 1 Schematic presentation of anatomical abnormalities in accordance with the classification of Masada K., Ono K. (1989)

A.R. Jo et al. retrospectively analysed the radiographs of 53 individuals with HMO (102 upper limbs) and supplemented the latter classification with two more types of deformities:
Type IV: osteocartilaginous exostoses located in the distal parts of both bones

Type IVA: osteocartilaginous exostoses located in the distal parts of both forearm bones combined with radial head dislocation;

Type IVB: osteocartilaginous exostoses located in the distal parts of both forearm bones without radial head dislocation (Fig. 2) [7].

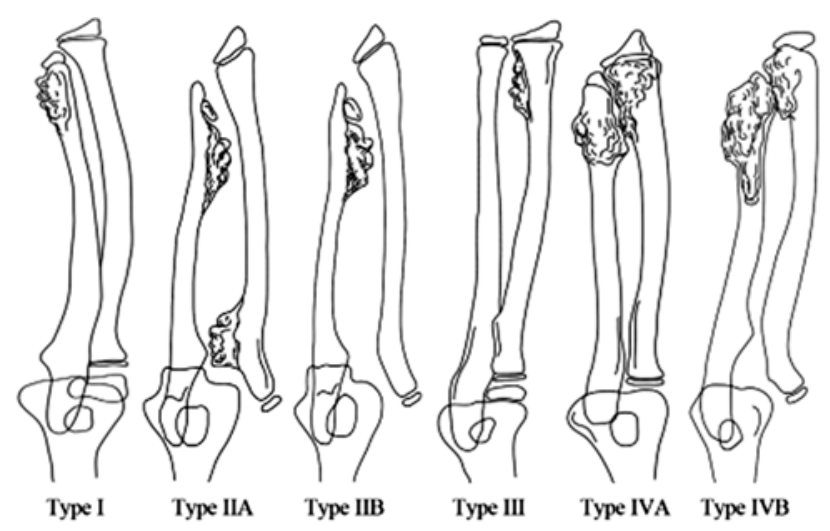

Fig. 2 Schematic presentation of anatomical abnormalities in accordance with the classification of Jo A.R., Jung S.T. (2017)

However, these classifications do not fully disclose the entire variety of deformities of the forearm bones in children due to osteocartilaginous exostoses, but indicate only the location of exostoses and the position of the head of the radius.

Thus, a combination of radial head dislocation with multiplanar deformities of the forearm bones leads to limitation of rotation and loss of function of the upper extremities [7-13]. Peterson suggested that preventing the development of forearm bone deformities in patients with $\mathrm{MHO}$, in particular radial head dislocation, is the most important goal of early surgical treatment [14].

The reference values of the long bone angles, proposed by Solomin L.N., have found application in the work of practicing orthopedists dealing with correction of deformities [15]. Most frequently, these angle values are used in the treatment of lower limb deformities. A few works has been devoted to correction of forearm deformities. There are scarce literature sources that describe deformities of the forearm bones in $\mathrm{MHO}$ patients not only from the point of location of exostoses and position of the head of the radius, but reveal true variants of deformities $[16,17]$. 
Understanding the development of deformities and their types, risk factors associated with the possibility of dislocation of the radial head will assist in identification of patients at risk who need early interventions to prevent functional disorders of the upper limb $[18,19]$.

The aim of the work was to study the deformities of the forearm bones in patients with multiple hereditary osteochondromas.

\section{MATERIAL AND METHODS}

Radiographs of the forearm bones in 84 patients (151 limbs) diagnosed with multiple hereditary at our institute from 2004 to 2018 were retrospectively analysed. Sixty-seven patients (80 \%) had bilateral lesions, and 17 patients (20\%) had lesions of only one upper limb. Patients were examined at preoperative planning; informed consent was obtained from patients or their legal representatives about the inclusion of their data in the study.

Patients were divided into groups according to Jo\& Jung's classification (modified classification of Masada). An orthopedic examination assessed the range of movements (supination / pronation); X-rays and computed tomography of the bones of both forearms were taken in two projections (anteroposterior, lateral). The deformities in the forearm bones were evaluated in accordance with the reference lines and angles: the proximal radial neck-shaft angle (PrNSA), the distal epidiphyseal angle of the radial bone (DEDA), "anatomical axis bowing" in every third for the forearm bones in the sagittal and frontal planes. The angle of inclination of the articular surface of the radius (RAA, radial articular angle), the angle of bowing of the radius ( $\mathrm{RB}$, radial bowing), and the shortening of the ulna with respect to the radius were also determined.

In accordance with the Jo\&Jung classification, the patients were divided into the following groups (comment: the number was calculated relative to all limbs (151), since one and the same patient could have Type 1 deformity in one limb and Type IV deformity in the other):

Type I (osteocartilaginous exostoses are located only in the distal ulna and there is no radial head dislocation) was detected in 37 patients ( $24 \%$ of cases). exostoses in the age of four to 17 years who were treated

Type III (osteocartilaginous exostoses are located in the distal radius and there is no radial head dislocation or radial shortening) was identified in 27 patients (18\%).

Type IVA group (osteocartilaginous exostoses are located in the distal parts of both bones combined with radial dislocation) was most numerous,71 patient (47\%).

Type IVB (osteocartilaginous exostoses are located in the distal parts of both bones without radial head dislocation) was detected in 13 patients (9\%).

Club hand of varying severity was present in $100 \%$ of cases. We revealed a significant preservation of both supination and pronation in patients with Type III of this pathology. A significant limitation of both supination and pronation was detected in patients with exostoses located in the distal part of both bones of the forearm. In this case, the dislocation of the radial head did not significantly affect the range of joint motion. The data obtained are presented in Table 1.

According to the findings of radiographic studies, we identified the deformities of the forearm bone, depending on the plane of their location. In all patients, regardless of the type of pathology according to the classification of Jo\&d Jung, there was varus of the ulna and radius and recurrent deformity of the ulna. As for the severity of deformities in the forearm bones, according to the accepted values of the reference angles, the smallest deformities (regardless of the plane) were found in the third type. Also, with this type, we did not reveal shortening of the ulna with respect to the radius, and in patients with Type IVB this shortening was significantly bigger as compared with the patients of other groups $(24.5 \pm 11.9 \mathrm{~mm})$.

The data obtained are presented in Table 2 .

Table 1

Supination/pronation in patients with HMO, depending on the type of pathology according to the classification of Jo\&Jung

\begin{tabular}{|l|c|c|c|c|}
\hline \multirow{2}{*}{ Parameter } & \multicolumn{4}{|c|}{ Type according to Jo\&Jung } \\
\cline { 2 - 5 } & I & III & IVA & IVB \\
\hline Supination (degrees) & $62.3 \pm 19.5$ & $80.7 \pm 8.5$ & $37 \pm 25.9$ & $29.2 \pm 25.9$ \\
\hline Pronation (degrees) & $73.9 \pm 20.9$ & $82.3 \pm 19.6$ & $55 \pm 30$ & $47.3 \pm 34.3$ \\
\hline
\end{tabular}


Table 2

Forearm bone deformities in patients with HMO, depending on the type of pathology according to the classification of Jo\&Jung

\begin{tabular}{|l|c|c|c|c|}
\hline \multirow{2}{*}{ Parameter } & \multicolumn{4}{c|}{ Type according to Jo and Jung } \\
\cline { 2 - 5 } & Type I & Type III & Type IVA & Type IVB \\
\hline $\begin{array}{l}\text { Varus of the ulna (number of } \\
\text { patients/\%/deformity in degrees) }\end{array}$ & $34 / 92 / 8.4 \pm 4.5$ & $23 / 85 / 4.1 \pm 2.6$ & $64 / 90 / 9.1 \pm 5.87$ & $12 / 92.3 / 15 \pm 8.3$ \\
\hline $\begin{array}{l}\text { Recurvatum of the ulna (number of } \\
\text { patients/\%/deformity in degrees) }\end{array}$ & $30 / 81 / 10.4 \pm 5.79$ & $15 / 55.5 / 7.5 \pm 6.2$ & $61 / 86 / 14.1 \pm 7.0$ & $10 / 77 / 12.6 \pm 5.45$ \\
\hline $\begin{array}{l}\text { Varus deformity of the radius } \\
\text { (number of patients/\%/deformity in } \\
\text { degrees) }\end{array}$ & $19 / 51 / 8.45 \pm 5.55$ & $4 / 14.8 / 2 \pm 1.1$ & $45 / 63.4 / 10.1 \pm 9.4$ & $8 / 66.7 / 11.2 \pm 11.6$ \\
\hline PrNSA of the radius(degrees) & $94 \pm 5.2$ & $91.6 \pm 6.7$ & $94.5 \pm 6.69$ & $98.9 \pm 65.5$ \\
\hline DEDA of the radius (degrees) & $67.3 \pm 4.78$ & $65.4 \pm 3.99$ & $63.6 \pm 6.75$ & $65 \pm 11.6$ \\
\hline Shortening of the radius (mm) & $14.8 \pm 8.4$ & none & $14.4 \pm 7.9$ & $24.5 \pm 11.9$ \\
\hline RAA (degrees) & $21.8 \pm 35.7$ & $20.4 \pm 9.8$ & $22.3 \pm 5.11$ & $20 \pm 28.6$ \\
\hline RB (degrees) & $10.2 \pm 0.8$ & $7.8 \pm 2.1$ & $8.7 \pm 1.67$ & $9.5 \pm 28.6$ \\
\hline
\end{tabular}

Thus, the deformities most frequently encountered were varus deformity at the border of upper and middle thirds and recurvatum at the border and middle thirds in the ulna while in the radius the most common was varus deformity in the middle and lower thirds as well as dislocation or subluxation of the radius (30\%). We found that varus deformity of the radius in the middle third was absent in the cases with radial head dislocation (11\%). There was a combination of the forearm deformity variants mentioned above such as varus recurvatum deformity of the radius at the border of the upper and middle thirds (55\% of cases), varus recurvatum deformity of the ulna at the border of the upper and midle thirds combined with varus of the radius in the middle third (15\% of cases).

RAA and RB values were not significantly different in the patients with forearm deformities according to Jo \& Jung's classification.

\section{DISCUSSION}

Long bone deformities have been sufficiently studied, as reported in domestic and international scientific journals. The authors mainly focus on the study and correction of long bone deformities of the lower extremities. The reference values of the angles of the ulna and radius and of epidiaphyseal angles of the radius were proposed after having conducted numerous retrospective analyses of radiographs [6, 20,21].

Also, 213 cases of multi-planar deformities of long bones (of which only 7 cases were patients with a diagnosis of "Multiple hereditary exostoses") were described [22]. Deformity severity at the preoperative stage was assessed using the reference lines and angles.

A few articles deal with forearm deformities, including the deformities of the forearm in this genetic disease of multiple hereditary [23-25].

The researchers focus on the investigation of such parameters of the forearm deformities in MHO as ulna shortening, presence/absence of radial head dislocation, location of exostoses in the metaphyseal bone part of the forearm bones. So, N.D. Clement and D.E. Porter stated that the magnitude of ulna shortening relative to the radius and the radial head dislocation are the risk factors of rotation limitation of the forearm bones and note the need of early surgical interventions in children [26-28].

Most of the authors opine that the indication for deformity correction in $\mathrm{MHO}$ is ulna shortening by $1.5 \mathrm{~cm}$ or radius shortening by more than $60 \%$, increase in RAA more than $30^{\circ}$, radial head instability and restrictions of motion in the wrist and elbow joints $[6,16]$. Ulna shortening averaged $14 \mathrm{~mm}$ in our patients that had types I и IVA of the deformities, and in type IVB it was up to $24.5 \pm 11.9 \mathrm{~mm}$ [26-30].

A.R. Jo and S.T. Jung proved statistically in their work that the proportion of ulna shortening to the radius as well as forearm bone bowing (RB) were predictive factors of radial head dislocation [7]. We did not reveal statistical significance of the RB angle value even in the group of patients with radial head dislocation. The RB angle was smaller in the group of patients with osteocartilaginous exostoses located in the distal radius without dislocation and radius shortening. 


\section{CONCLUSION}

The variety of forearm deformities in children the indications for surgical intervention, depending on due to HMO requires a differentiated approach to the deformity type and the specific clinical situation. the choice of an individual, in each case, surgical To date, this issue remains unresolved and much treatment technique. It is important to clearly establish discussed.

Source of funding The study was financially supported by the FSBI Turner Scientific and Research Institute for Children's Orthopedics of the Ministry of Health of the Russian Federation.

Conflict of interest The authors declare no apparent or potential conflicts of interest related to the publication of this article.

Ethical Expertise Patients and their representatives gave their consent to processing and publication of personal data.

\section{REFERENCES}

1. Volkov M.V. Kostnaia patologiia detskogo vozrasta: (Opukholevye i displasticheskie zabolevaniia kostei) [Bone Pathology of Childhood: (Tumor-related and dysplastic bone diseases)]. M., Meditsina, 1968, 496 p. (in Russian)

2. Berglezov M.A., Meerson E.M., Samoilova L.I., Feshchenko S.P., Barer F.S., Bruskina V.Ia., Razzokov A.A. Kliniko-geneticheskii analiz mnozhestvennoi ekzostoznoi khondrodisplazii [Clinical-and-genetic analysis of multiple exostose chondrodysplasia]. Tez. dokl. $V$ Vsesoiuznogo Sezda Travmatologov-ortopedov SSSR [Proc. V All-Russian Congress of Traumatologists-Orthopedists of the USSR]. Moscow, 1988, part 2, pp. 147-148. (in Russian)

3. Khodzhaeva L.Iu. Khirurgicheskoe lechenie deformatsii predplechia u detei pri ekzostoznoi khondrodisplazii. Synopsis. Diss. kand. med. nauk [Surgical treatment of the forearm deformities in children with exostose chondrodysplasia. Cand. med. sci. diss.]. SPb., 1999. 23 p. (in Russian)

4. Porter D.E., Emerton M.E., Villanueva-Lopez F., Simpson A.H. Clinical and radiographic analysis of osteochondromas and growth disturbances in hereditary multiple exostoses. J. Pediatr. Orthop., 2000, vol. 20, no. 2, pp. 246-250.

5. Masada K., Tsuyuguchi Y., Kawai H., Kawabata H., Noguchi K., Ono K. Operations for forearm deformity caused by multiple osteochondromas. J. Bone Joint Surg. Br., 1989, vol. 71, no. 1, pp. 24-29.

6. Legeai-Mallet L., Munnich A., Maroteaux P., Le Merrer M. Incomplete penetrance and expressivity skewing in herebitary multiple exostoses. Clin. Genet., 1997, vol. 52, no. 1, pp. 12-16.

7. Jo A.R., Jung S.T., Kim M.S., Oh C.S., Min B.J. An Evaluation of Forearm Deformities in Hereditary Multiple Exostoses: Factors Associated With Radial Head Dislocation and Comprehensive Classification. J. Hand Surg. Am., 2017, vol. 42, no. 4, pp. 292. e1-292.e8. DOI: 10.1016/j.jhsa.2017.01.010.

8. El-Sobky T.A., Samir S., Atiyya A.N., Mahmoud S., Aly A.S., Soliman R. Current paediatric orthopaedic practice in hereditary multiple osteochondromas of the forearm: a systematic review. SICOT J., 2018, vol. 4, pp. 10. DOI: 10.1051/sicotj/2018002.

9. Ham J., Flipsen M., Koolen M., Van der Zwan A., Mader K. Multiple osteochondromas (MO) in the forearm: a 12-year single-centre experience. Strategies Trauma Limb Reconstr., 2016, vol. 11, no. 3, pp. 169-175.

10.Refsland S., Kozin S.H., Zlotolow D.A. Ulnar Distraction Osteogenesis in the Treatment of Forearm Deformities in Children with Multiple Hereditary Exostoses. J. Hand Surg. Am., 2016, vol. 41, no. 9, pp. 888-895. DOI: 10.1016/j.jhsa.2016.06.008.

11.Tang Z.W., Cao Y.L., Liu T., Chen T., Zhang X.S. Management of forearm deformities with ulnar shortening more than $15 \mathrm{~mm}$ caused by hereditary multiple osteochondromas. Eur. J. Orthop. Surg. Traumatol., 2013, vol. 23, no. 5, pp. 611-618. DOI: 10.1007/ s00590-012-1033-9.

12.Vogt B., Tretow H.L., Daniilidis K., Wacker S., Buller T.C., Henrichs M.P., Roedl R.W., Schiedel F. Reconstruction of forearm deformity by distraction osteogenesis in children with relative shortening of the ulna due to multiple cartilaginous exostosis. J. Pediatr. Orthop., 2011, vol. 31, no. 4, pp. 393-401. DOI: 10.1097/BPO.0b013e31821a5e27.

13.Woodside J.C., Ganey T., Gaston R.G. Multiple osteochondroma of the hand: initial and long-term follow-up study. Hand (N.Y.), 2015, vol. 10, no. 4, pp. 616-620. DOI: 10.1007/s11552-015-9775-6.

14.Ishikawa J., Kato H., Fujioka F., Iwasaki N., Suenaga N., Minami A. Tumor location affects the results of simple excision for multiple osteochondromas in the forearm. J. Bone Joint Surg. Am., 2007, vol. 89, no. 6, pp. 1238-1247. DOI: 10.2106/JBJS.F.00298.

15.Peterson H.A. Deformities and problems of the forearm in children with multiple hereditary osteochondromata. J. Pediatr. Orthop., 1994, vol. 14, no. 1, pp. 92-100. DOI: 10.1097/01241398-199401000-00019.

16.Solomin L.N., Shchepkina E.A., Kulesh P.N., Vilenskii V.A., Korchagin K.L., Skomoroshko P.V., comp. Opredelenie referentnykh linii i uglov dlinnykh trubchatykh kostei: posobie dlia vrachei [Determination of reference lines and angles of long tubular bones: manual for physicians)]. SPb., RNIITO im. R.R. Vredena, 2012, 48 p. (in Russian)

17.Shin E.K., Jones N.F., Lawrence J.F. Treatment of multiple hereditary osteochondromas of the forearm in children: a study of surgical procedures. J. Bone Joint Surg. Br., 2006, vol. 88, no. 2, pp. 255-260. DOI: 10.1302/0301-620X.88B2.16794.

18.Litzelmann E., Mazda K., Jehanno P., Brasher C., Penneçot G.F., Ilharreborde B. Forearm deformities in hereditary multiple exostosis: clinical and functional results at maturity. J. Pediatr. Orthop., 2012, vol. 32, no. 8, pp. 835-841. DOI: 10.1097/ BPO.0b013e3182694e40.

19.Iba K., Hanaka M., Ozasa Y., Takahashi N., Kanaya K., Yamashita T. Treatment of forearm deformity with radial head dislocation because of multiple osteochondromas: a series of three cases treated by simple axis correction and distraction osteogenesis of the ulna. J. Pediatr. Orthop. B, 2018, vol. 27, no. 4, pp. 315-321. DOI: 10.1097/BPB.0000000000000453. 
20.Li Y., Han B., Tang J., Chen M., Wang Z. Identification of risk factors affecting bone formation in gradual ulnar lengthening in children with hereditary multiple exostoses: A retrospective study. Medicine, 2019, vol. 98, no. 5, e14280. DOI: 10.1097/ MD.0000000000014280.

21.Beutel B.G., Klifto C.S., Chu A. Timing of forearm deformity correction in a child with multiple hereditary exostosis. Am. J. Orthop. (Belle Mead NJ), 2014, vol. 43, no. 9, pp. 422-425.

22.D’Ambrosi R., Barbato A., Caldarini C., Biancardi E., Facchini R.M. Gradual ulnar lengthening in children with multiple exostoses and radial head dislocation: results at skeletal maturity. J. Child. Orthop., 2016, vol. 10, no. 2, pp. 127-133. DOI: 10.1007/s11832016-0718-8.

23.Vilenskii V.A., Pozdeev A.A., Zubairov T.F., Zakharian E.A., Pozdeev A.P. Lechenie detei s deformatsiiami dlinnykh trubchatykh kostei nizhnikh konechnostei metodom chreskostnogo osteosinteza s ispolzovaniem apparata Orto-SUV: analiz 213 sluchaev [Treatment of children with deformities of long tubular bones of the lower limbs by transosseous osteosynthesis method using Ortho-SUV frame: analysis of 213 cases]. Ortopediia, Travmatologiia i Vosstanovitelnaia Khirurgiia Detskogo Vozrasta, 2016, vol. 4, no. 4, pp. 21-32. (in Russian)

24.Cho Y.J., Jung S.T. Gradual lengthening of the ulna in patients with multiple hereditary exostoses with a dislocated radial head. Yonsei Med. J., 2014, vol. 55, no. 1, pp. 178-184. DOI: 10.3349/ymj.2014.55.1.178.

25.Stanton R.P., Hansen M.O. Function of the upper extremities in hereditary multiple exostoses. J. Bone Joint Surg. Am., 1996, vol. 78, no. 4, pp. 568-573. DOI: 10.2106/00004623-199604000-00010.

26.Eralp L., Bilen F.E., Rozbruch S.R., Kocaoglu M., Hammoudi A.I. External fixation reconstruction of the residual problems of benign bone tumours. Strategies Trauma Limb Reconstr., 2016, vol. 11, no. 1, pp. 37-49. DOI: 10.1007/s11751-016-0244-8.

27.Massobrio M., Antonietti G., Pellicanò G., Necci F. Single forearm radius and ulna asymmetric lengthening in multiple cartilaginous exostoses: a case report and a long-term follow-up. J. Pediatr. Orthop. B, 2015, vol. 24, no. 6, pp. 561-566. DOI: 10.1097/ BPB.0000000000000212.

28.Ahmed AARY. Gradual ulnar lengthening by an Ilizarov ring fixator for correction of Masada IIb forearm deformity without tumor excision in hereditary multiple exostosis: preliminary results. J. Pediatr. Orthop. B, 2019, vol. 28, no. 1, pp. 67-72. DOI: 10.1097/ BPB.0000000000000514.

29.Clement N.D., Porter D.E. Forearm deformity in patients with hereditary multiple exostoses: factors associated with range of motion and radial head dislocation. J. Bone Joint Surg. Am., 2013, vol. 95, no. 17, pp. 1586-1592. DOI: 10.2106/JBJS.L.00736.

30.Noonan K.J., Levenda A., Snead J., Feinberg J.R., Mih A. Evaluation off the forearm in untreated adult subjects with multiple hereditary osteochondromatosis. J. Bone Joint Surg. Am., 2002, vol. 84, no. 3, pp. 397-403. DOI: 10.2106/00004623-20020300000010.

31.Bauer A.S., Storelli D.A.R., Sibbel S.E., McCarroll H.R., Lattanza L.L. Preoperative computer simulation and patient-specific guides are safe and effective to correct forearm deformity in children. J. Pediatr. Orthop., 2017, vol. 37, no. 7, pp. 504-510. DOI: 10.1097/BPO.0000000000000673.

Received: 24.07.2019

\section{Information about the authors:}

1.Ekaterina A. Zakharyan, M.D., Ph.D., The Turner Scientific and Research Institute for Children's Orthopedics, Saint Petersburg, Russian Federation, Email: zax-2008@mail.ru

2. Ekaterina A. Belousova, M.D., North-Western State Medical University named after I.I. Mechnikov, Saint Petersburg, Russian Federation, Email: qeen18@mail.ru

3. Alexander P. Pozdeev, M.D., Ph.D., Professor, The Turner Scientific and Research Institute for Children's Orthopedics, Saint Petersburg, Russian Federation, Email: prof.pozdeev@mail.ru 